\title{
A UTILIZAÇÃO DO SOFTWARE QDA MINER LITE NAS PESQUISAS QUE UTILIZAM A ANÁLISE TEXTUAL DISCURSIVA
}

\section{USE OF THE QDA MINER LITE SOFTWARE PROGRAM IN RESEARCH WITH THE DISCURSIVE TEXTUAL ANALYSIS}

\author{
Leonir Lorenzetti ${ }^{1}$ \\ Tamara Dias Domiciano ${ }^{2}$ \\ Ana Paula Geraldo ${ }^{3}$
}

\begin{abstract}
Resumo: No desenvolvimento de pesquisas, a análise dos dados pode ser considerada como a etapa mais exaustiva e a mais importante na produção e na disseminação de novos conhecimentos. Este trabalho descreve como o QDA Miner Lite foi utilizado na análise dos dados de duas pesquisas diferentes. Em ambos os casos a análise foi constituída por desconstrução do corpus, unitarização e categorização - etapas metodológicas da Análise Textual Discursiva. O estudo caracteriza-se como pesquisa qualitativa e documental. As discussões realizadas apontam as contribuições do software, que, aliado à metodologia da Análise Textual Discursiva, indicou melhora na qualidade das investigações e auxílio no aprofundamento nas interpretações dos dados constituídos. O estudo deixou claro que o software não implica a exclusão do pesquisador no processo de análise, mas que seu uso refina a organização do trabalho, propiciando compreensão mais consistente do que está sendo investigado.
\end{abstract}

Palavras-chave: Análise Textual Discursiva; Pesquisa Qualitativa; Software de Análise; QDA Miner Lite.

\begin{abstract}
In the development of research, data analysis can be considered the most exhaustive and the most important stage in the production and dissemination of new knowledge. This work describes how the QDA Miner Lite was used to analyze data from two different works. In both cases, the analysis was constituted by deconstruction of the corpus, unitarization and categorization - methodological stages of the Discursive Textual Analysis. The study is characterized as qualitative and documentary research. The discussions pointed out the contributions of the software, which, combined with the Discursive Textual Analysis methodology, indicated an improvement in the quality of the investigations and positive assistance in the interpretations of the constituted data. The study made it clear that the software does not imply the exclusion of the researcher in the analysis process, but that its use refines the organization of the work, providing a more consistent understanding of what is being investigated.
\end{abstract}

Keywords: Discursive Textual Analysis; Qualitative Research; Analysis Software; QDA Miner Lite.

\footnotetext{
${ }^{1}$ Doutor em Educação Científica e Tecnológica pela Universidade Federal de Santa Catarina (UFSC). Professor da Universidade Federal do Paraná (UFPR). Curitiba, Paraná, Brasil. E-mail: leonirlorenzetti22@gmail.com

${ }^{2}$ Mestra e Doutoranda do Programa de Educação em Ciências e em Matemática da Universidade Federal do Paraná (UFPR). Curitiba, Paraná, Brasil. E-mail: tamydomiciano@gmail.com

${ }^{3}$ Mestra pelo Programa de Educação em Ciências e em Matemática da Universidade Federal do Paraná (UFPR). Professora nas Prefeituras Municipais de Curitiba e São José dos Pinhas, Paraná, Brasil. E-mail: anapaulageraldo.apg@gmail.com
} 


\section{Introdução}

O planejamento, desenvolvimento e a comunicação de um trabalho, como monografias, Trabalho de Conclusão de Curso, dissertações, teses e artigos exigem um conjunto de elementos para que seja caracterizado como pesquisa acadêmica, na medida em que amplia o conhecimento numa determinada área do conhecimento.

Por mais que uma parcela de discentes vivenciem experiências voltadas para a iniciação científica na Graduação, é nos programas de Pós-Graduação que ocorre uma discussão mais aprofundada dos princípios que balizam uma pesquisa acadêmica. Nos programas de Pós-Graduação, principalmente no mestrado, é recorrente a oferta de disciplinas como Seminários de Pesquisa, que oferece um aprofundamento dos fundamentos da pesquisa, das etapas e dos encaminhamentos metodológicos.

Em termos de metodologia, são apresentados a natureza da pesquisa, os distintos tipos de pesquisa, as técnicas de constituição de dados e as metodologias de análise. É o momento em que o pós-graduando faz as suas escolhas metodológicas, balizado pelo problema de pesquisa que norteia sua investigação.

É notório que uma grande parcela dos mestrandos apresenta dificuldades para fazer as escolhas, bem como analisar as implicações das escolhas para o desenvolvimento da pesquisa. Para tanto, é necessário compreender o ciclo de pesquisa.

De acordo com Minayo (1994), o ciclo de pesquisa apresenta três etapas: fase exploratória, trabalho de campo e tratamento do material. Toda pesquisa inicia com a fase exploratória, em que são discutidos os aspectos referentes ao objeto, aos pressupostos, às teorias pertinentes, à metodologia apropriada e às questões operacionais necessárias para conduzir o trabalho de campo. O trabalho de campo consiste no recorte empírico da pesquisa, sendo utilizadas uma ou mais técnicas de constituição de dados, como entrevistas, observações, questionários, diários de bordo, entre outros. Por fim, faz-se necessário planejar a forma de realizar a análise dos dados constituídos durante a investigação, que pode ser subdividida em: ordenação, classificação e análise.

Sabemos que as pesquisas de natureza qualitativa geram um enorme volume de dados que precisam ser organizados e compreendidos, requerendo assim um processo continuado em que se procura identificar dimensões, categorias, tendências, padrões, relações, desvendando-lhes o significado. Esse processo é complexo, não-linear e implica um trabalho de redução, organização e interpretação dos dados que se inicia já na fase exploratória e acompanha todo o ciclo da investigação (TEIXEIRA, 2003). 
A análise tem como objetivo organizar e sumariar os dados de tal forma que possibilitem o fornecimento de respostas ao problema proposto para investigação. Já a interpretação tem como objetivo a procura do sentido mais amplo das respostas, o que é feito mediante sua ligação a outros conhecimentos anteriormente obtidos (GIL, 1999, p. 168).

A metodologia de análise, por sua vez, tradicionalmente aparesenta as seguintes abordagens: análise de conteúdo (BARDIN, 1977), análise textual discursiva (MORAES; GALIAZZI, 2006), análise de discurso (ORLANDI, 2003), Grounded Theory (CHARMAZ, 2012), hermenêutica (GRONDIN, 2012), Teoria Fundamentada (CHARMAZ, 2009), entre outras.

Considerando o volume de dados constituídos em pesquisa qualitativa e os avanços tecnológicos, tem sido cada vez mais recorrente o uso de software para análises de dados. O estudo de Salvador et al., (2019) identificou e mapeou o uso de softwares de análise de dados qualitativos utilizados nas pesquisas desenvolvidas no âmbito dos Programas de Pós-Graduação da enfermagem brasileira, utilizando o Banco de Teses e Dissertações da Coordenação de Aperfeiçoamento de Pessoal de Nível Superior. Os autores localizaram 239 trabalhos, conforme Tabela 1:

\begin{tabular}{|lcc|}
\hline \multicolumn{3}{|c|}{$\begin{array}{c}\text { Tabela 1 - Softwares de análise de dados qualitativos utilizados nas } \\
\text { dissertações e teses analisadas. Natal, RN, Brasil, 2017. (n=239) }\end{array}$} \\
\hline Software & $\mathrm{n}$ & $\%^{*}$ \\
\hline Atlas.ti & 58 & 24,3 \\
Alceste & 47 & 19,7 \\
NVivo & 42 & 17,6 \\
IRAMUTEQ & 37 & 15,5 \\
EVOC & 30 & 12,6 \\
Qualiquantisoft & 12 & 5,0 \\
Ethnograph & 6 & 2,5 \\
Tri-deux-mots & 6 & 2,5 \\
WebQDA & 5 & 2,1 \\
MaxQDA & 3 & 1,3 \\
OpenLogos & 3 & 1,3 \\
\hline "A soma é superior a 100\% pois 10 trabalhos utilizaram mais de um software. \\
\hline
\end{tabular}

Fonte: Salvador et al., (2019, p. 6).

Em vista do exposto, este trabalho teve por finalidade descrever o uso do QDA Miner Lite em duas pesquisas, no processo de desconstrução do corpus, unitarização e categorização, etapas da metodologia de Análise Textual Discursiva. As pesquisas analisadas foram desenvolvidas no Grupo de Estudos e Pesquisas em Alfabetização Científica e Tecnológica (GEPACT) na Universidade Federal do Paraná. O GEPACT objetiva estudar as concepções, as práticas e as tendências da Alfabetização Científica e Tecnológica na Educação em Ciências, com ênfase na articulação entre ensino, pesquisa e extensão. Envolve os estudos sobre Alfabetização Científica e Tecnológica, a 
abordagem das relações entre Ciência, Tecnologia e Sociedade, a Educação Ambiental, bem como estudos que discutem o papel na Educação Científica na Educação Básica ou na formação de professores de ciências no espaço formal e não formal.

\section{Análise Textual Discursiva}

A Análise Textual Discursiva (ATD) é um método de organização, interpretação e comunicação utilizado em pesquisas das áreas das ciências sociais, a qual está situada entre a análise de conteúdo e a análise do discurso. Nas pesquisas qualitativas, a ATD se mostra em ascenção uma vez que permite ao pesquisador flexibilidade na interpretação dos dados constituídos (MORAES; GALIAZZI, 2006). Assim, essa metodologia de análise

[...] pode ser compreendida como um processo auto organizado de construção de compreensão em que novos entendimentos emergem a partir de uma sequência recursiva de três componentes: a desconstrução dos textos do 'corpus', a unitarização, o estabelecimento de relações entre os elementos unitários, a categorização; o captar emergente em que a nova compreensão é comunicada e validada (MORAES; GALIAZZI, 2011, p. 12).

Desse modo, a ATD objetiva, por meio da desconstrução de textos de gêneros diversos, a interpretação aprofundada do conteúdo elencado como corpus, levando o pesquisador a ressignificar e, não somente, identificar comprovações, fazer refutações e elaborar hipóteses (MORAES; GALIAZZI, 2011). Segundo Moraes e Galiazzi (2011), essa metodologia possibilita que o pesquisador construa significados, tendo como base as teorias e seu ponto de vista, levando-o a assumir-se como autor sobre o que interpreta a partir do material analisado (MORAES; GALIAZZI, 2011).

A Análise Textual Discursiva ocorre por meio de três elementos: "[...] a unitarização - desconstrução dos textos do corpus; a categorização - estabelecimento de relações entre os elementos unitários; e por último o captar de um novo emergente em que a nova compreensão é comunicada e validada" (MORAES, 2003, p. 192).

A primeira etapa, desmontagem dos textos, compreende a desconstrução e unitarização do texto do corpus da pesquisa. O corpus da pesquisa parte de um conjunto de documentos que são analisados, que podem tanto ser produzidos para a investigação quanto pré-existentes. Assim, a unitarização é o momento, segundo Moraes e Galiazzi (2006), em que se desorganiza o organizado por meio da fragmentação e desconstrução dos textos do corpus. Ao buscar por significados, sentidos e a relação estreita com os 
dados, o pesquisador vai identificando e elencando as unidades de sentido e/ou significado.

A unitarização ocorre em três fases: I) desconstrução do texto e codificicação por expressões de cada unidade de sentido; II) o movimento de reescrita da unidade de sentido para que seu significado seja o mais completo possível; III) a atribuição de nome ou título para cada unidade elaborada (MORAES; GALIAZZI, 2011).

Moraes e Galiazzi (2006) explicam que as unidades de sentido são palavras, frases e até mesmo parágrafos retirados pelo pesquisador dos textos que compõem o corpus de análise. Nesse processo, de elencar as unidades de sentido, vão se elaborando expressões ou termos que as identifiquem, sendo necessário que as unidades de sentido sejam coerentes com seu contexto textual original.

Após a unitarização segue-se para a categorização, que ocorre com base nos significados semelhantes, podendo resultar em diversos níveis de categorias. $\mathrm{Na}$ categorização, o intuito é estabelecer e construir relações com e entre as unidades de sentido, por meio da classificação e da reunião de elementos unitários que podem formar conjuntos e gerar categorias (MORAES; GALIAZZI, 2011, p. 12). Em visto disso, as categorias podem ser identificadas a partir da análise e compreensão de elementos de semelhança entre as unidades de sentido.

Durante a categorização podem ser construídos diferentes níveis de categorias, sendo que, em alguns casos, elas assumem as denominações de iniciais, intermediárias e finais, constituindo, cada um dos grupos, na ordem apresentada, categorias mais abrangentes e em menor número (MORAES; GALIAZZI, 2011, p. 23). Assim, as categorias podem ser a priori ou emergentes:

As primeiras correspondem a construções que o pesquisador elabora antes de realizar a análise propriamente dita dos dados. Provêm das teorias em que fundamenta o trabalho e são obtidas por métodos dedutivos. Já as categorias emergentes são construções teóricas que o pesquisador elabora a partir do 'corpus'. Conforme já proposto, uma terceira alternativa constitui um modelo misto de categorias, no qual o pesquisador parte de um conjunto de categorias definido 'a priori', complementando-as ou reorganizando-as a partir da análise (MORAES; GALIAZZI, 2011, p. 25).

A elaboração de categorias é fluída, podendo elas serem modificadas e reorganizadas ao longo do processo da análise. É também com a construção de categorias que se inicia a escrita dos metatextos. A construção dos metatextos, por sua vez, pode ocasionar novas categorias e subcategorias relacionadas aos temas centrais das categorias-base (MORAES, 2003). 
Uma vez construídas as categorias, estabelecem-se pontes entre elas, investigam-se possíveis sequências em que poderiam ser organizadas, sempre no sentido de expressar com maior clareza as novas intuições e compreensões atingidas (MORAES, 2003, p. 202).

Moraes e Galiazzi (2011, p. 26) argumentam que para as categorias serem válidas e pertinentes, elas “[...] necessitam ser homogêneas, ou seja, precisam ser construídas a partir de um mesmo princípio, a partir de um mesmo contínuo conceitual”. Ainda, além da descrição do que foi identificado, as categorias apresentam uma nova compreensão sobre o universo investigado aliada aos movimentos de interpretação do pesquisador. Desse modo, "para comunicar o novo emergente não basta apenas descrições minuciosas dos dados constituídos, mas a interpretação e teorização dos metatextos" (GERALDO, 2020, p. 93).

À vista disso, o último elemento da ATD é a construção dos metatextos, que carregam os sentidos construídos sobre o universo investigado. Os textos produzidos por meio da ATD podem seguir duas diferentes ênfases, sendo descritivos: reproduzindo mais fielmente o corpus da pesquisa; ou interpretativos: expressando uma maior abstração e teorização sobre os dados constituídos na investigação (MORAES; GALIAZZI, 2011).

É durante a construção do metatexto que o autor produz argumentos e teses para as categorias e para a análise como um todo.

Entendemos que criar esses argumentos aglutinadores não representa apenas
uma das contribuições mais significativas e originais do pesquisador, como
também estabelecerá as condições para a estruturação de um texto coerente e
consistente. A tese geral servirá de elemento estruturador e organizador de
todos os componentes do texto, permitindo não apenas fugir da excessiva
fragmentação, mas também possibilitando ao pesquisador assumir-se
efetivamente autor de seu texto (MORAES; GALIAZZI, 2011, p. 33).

O pesquisador, então, não é apenas um elemento externo à pesquisa, mas parte integrante dela, assumindo-se como autor e produtor de sentidos e significados sobre o que estuda. E mais do que apenas expor aquilo que já se sabe, a construção dos textos é um processo vivo e dinâmico que oportuniza a aprendizagem constante sobre o universo investigado (MORAES; GALIAZZI, 2011).

Para elucidar as etapas da Análise Textual Discursiva, apresenta-se o Quadro 1, construído a partir de pesquisas realizadas no âmbito do Grupo de Estudos e Pesquisa em Alfabetização Científica e Tecnológica (GEPACT-UFPR). 
Quadro 1: Fases da Análise Textual Discursiva

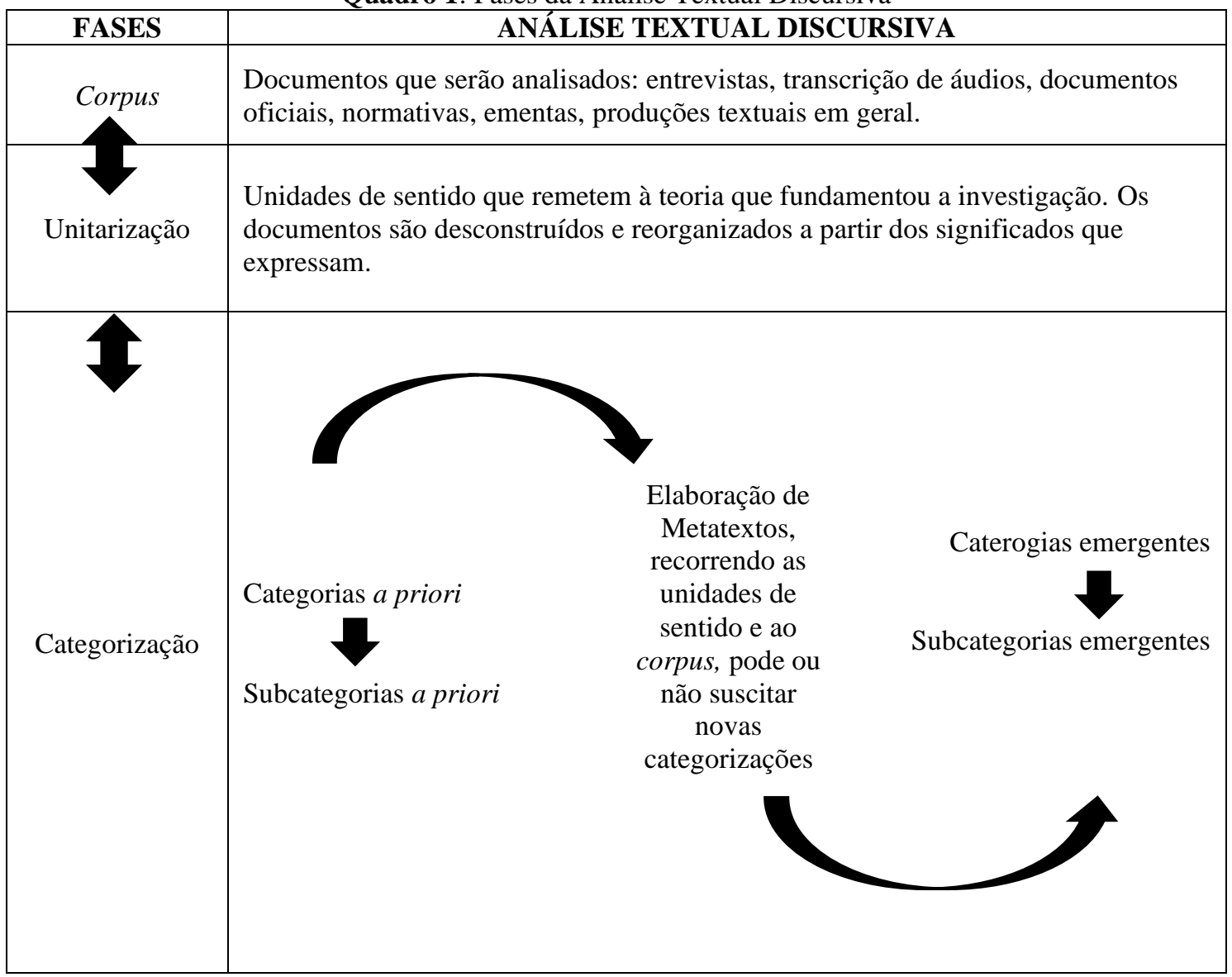

Fonte: Os autores (2020)

Em suma, a Análise Textual Discursiva é um processo dinâmico de leitura e releitura de materiais, com movimentos de aproximação e afastamento que, por meio do exercício contínuo do pesquisador e de sua interpretação, possibilita novas compreensões sobre o que se busca investigar.

\subsection{Softwares de análise qualitativa}

Atualmente se observa uma ascendência na utilização de softwares de análises quantitativas e qualitativas que se propõem a facilitar a organização, categorização e agrupamento dos dados. Iniciativas privadas e de grupos de pesquisa de Universidades Federais no Brasil estão criando, adequando e aprimorando tais softwares, visando layout e interface mais intuitivos e sistemas de colaboração online, onde pesquisadores, em diferentes locais, possam fazer análises de um mesmo corpus em tempo real (GARCIA; ESTEVÃO, 2016; NERI de SOUZA; NERI de SOUZA; COSTA, 2014).

Entretanto, conforme Flick (2005) argumenta, a chegada de tais recursos tecnológicos não gerou uma visão totalmente positiva, pois havia uma desconfiança, por 
parte da comunidade de pesquisadores, que essas ferramentas viessem a descaracterizar a pesquisa qualitativa. Porém, conforme o mesmo autor, softwares de análises qualitativas fornecem ao pesquisador condições mais objetivas e fidedignas de organização e codificação em sua análise, sendo o trabalho reflexivo e crítico do pesquisador essencial durante todo o processo.

Mais especificamente, os softwares de análise do tipo QDA (qualitative data analysis) são ferramentas digitais de análise qualitativa, que podem ser encontradas em plataformas gratuitas e também pagas. O QDA auxilia no processo da desconstrução, identificação de excertos significativos, ao problema de pesquisa elencado e na categorização do corpus. O pesquisador pode importar seu material, seja ele textual ou uma imagem, em diferentes formatos de arquivo, para o QDA, que por sua vez disponibiliza uma série de elementos para edição e agrupamamento das análises. Assim, realizando leituras minuciosas, o pesquisador consegue criar e organizar códigos e subcódigos em seu processo de análise. Por fim, os excertos que formam as categorias e/ou subcategorias podem ser exportadas para planilhas e gráficos e ficam disponíveis para download e compartilhamento.

Neri de Souza, Neri de Souza e Costa (2014) explicitam que tecnologias vêm sendo integradas amplamente nas pesquisas, seja pela forma de busca de artigos e documentos em plataformas oficiais do governo e repositórios, seja no processo de organização e análise dos resultados. Contudo, os mesmos autores identificaram em uma consulta no Banco de Teses e Dissertações da CAPES que ainda são escassas as pesquisas dentro das áreas das ciências humanas e sociais que investiguem como as tecnologias no processo de análise qualitativa estão sendo utilizadas.

Portanto, há a necessidade de pesquisas que se dediquem a apresentar como decorre a análise por meio de softwares e de formações que deem subsídios para o uso de ferramentas de análises qualitativas, as quais podem otimizar, simplificar e tornar o processo de análise mais fidedigno. Contudo, apenas instrumentalizar o pesquisador não é o que se almeja. Uma inserção e apropriação crítica da tecnologia é o caminho mais adequado quando se pensa na formação de pesquisadores capazes de compreender o mundo permeado por ferramentas tecnológicas.

Para tanto, Neri de Souza, Neri de Souza e Costa (2014) explicam que, ao se propor o uso de ferramentas digitais de análises, questões elementares como qual melhor QDA a se usar até questões mais complexas, relacionadas a própria metodologia de análise, precisam ser feitas pelo pesquisador. Nesse sentido, tais reflexões, segundo os 
mesmos autores, seriam relacionadas a: I) de que forma o QDA contribui para a minha pesquisa?; II) O QDA pode me ajudar a percorrer pelas diferentes nuances metodológicas que minha pesquisa requer?; III) O QDA possui elementos analíticos suficientes para a minha análise? Desse modo, é necessário ao pesquisador ter muito claro seu problema de pesquisa, objetivos específicos, materiais empíricos para a constituição de dados e domínio da metodologia analítica, para que o uso dos QDAs seja relevante em sua pesquisa.

Se por um lado o QDA vem possibilitando aos pesquisadores maior agilidade na organização de sua pesquisa, por outro pode-se observar avanços tecnológicos nas áreas de inteligência artificial os quais, muitas vezes, são acríticos. Portanto, aos pesquisadores e grupos de pesquisa fica o compromisso da busca pela compreensão de tais ferramentas, seus prós e contras e formas reflexivas de apropriá-las à atividade de pesquisa.

\section{Metodologia}

O estudo caracteriza-se como uma pesquisa de natureza qualitativa e utilizou a pesquisa documental para a constituição dos dados.

O Grupo de Estudos e Pesquisas em Alfabetização Científica e Tecnologia (GEPEACT) da Programa de Pós-Graduação em Educação em Ciências e em Matemática da Universidade Federal do Paraná desenvolveram, no período de 2015 a 2020, 14 dissertações, sendo que 10 delas utilizaram a análise textual discursiva no processo de análise dos dados. Destas, somente 2 utilizaram o QDA Miner Lite como suporte na análise dos dados. Quanto a dissertações em andamento, 3 delas fazem uso do QDA Miner Lite.

A dissertação de Domiciano (2019) analisou as abordagens do enfoque CTS presentes no Projeto Pedagógico do Curso de Licenciatura em Ciências da UFPR Litoral, na percepção e na prática dos docentes formadores. Para a constituição dos dados a autora analisou: a) o Projeto Pedagógico do Curso; b) as atividades desenvolvidas por professores do curso em dois módulos, sendo eles de "concepções de ciência e educação" e "vivências de docência, relação ciência e sociedade e prática de ensino"; c) entrevistas realizadas com quatro os professores formadores, que ministravam os módulos.

A dissertação de Geraldo (2020) analisou como se desenvolve a prática pedagógica no componente curricular híbrido Ciências Aplicadas, ministrado no Ensino Médio do Colégio SESI-Paraná, em uma turma interseriada. No processo de constituição 
de dados a autora analisou: a) a proposta curricular diversificada do componente híbrido Ciências Aplicadas e a Matriz de Referência do Segmento 8 - Sociedade e Sustentabilidade; b) entrevista com o responsável por elaborar a proposta curricular e a Matriz de Referência; c) observação das aulas do componente curricular híbrido Ciências Aplicadas, do Segmento 8 - Sociedade e Sustentabilidade, durante um trimestre; d) entrevista com o docente de Ciências Aplicadas que teve suas aulas observadas. Os dados foram analisados por meio da Análise Textual Discursiva.

\section{QDA Miner Lite e a Análise Textual Discursiva}

O software QDA Miner é uma ferramenta de análise qualitativa que permite a análise de documentos, artigos, livros, entrevistas transcritas ou arquivos de texto em geral, bem como pinturas, desenhos, fotografias e materiais visuais. A fabricante, Provalis Research, disponibiliza em seu site duas versões da ferramenta, o QDA Miner 6.0, que é a versão paga do recurso, com variação de valores a partir do perfil de consumo (para fins comerciais, governamentais ou acadêmicos) e forma de licença do produto (atualização do recurso, licença anual ou licença permanente). Já o QDA Miner Lite, descrito neste artigo, é a versão gratuita do software com licença permanente, mas com recursos limitados que, por sua vez, não comprometem a qualidade da análise realizada. A Figura 1 apresenta a interface do programa. 
Figura 1: Interface QDA Miner Lite

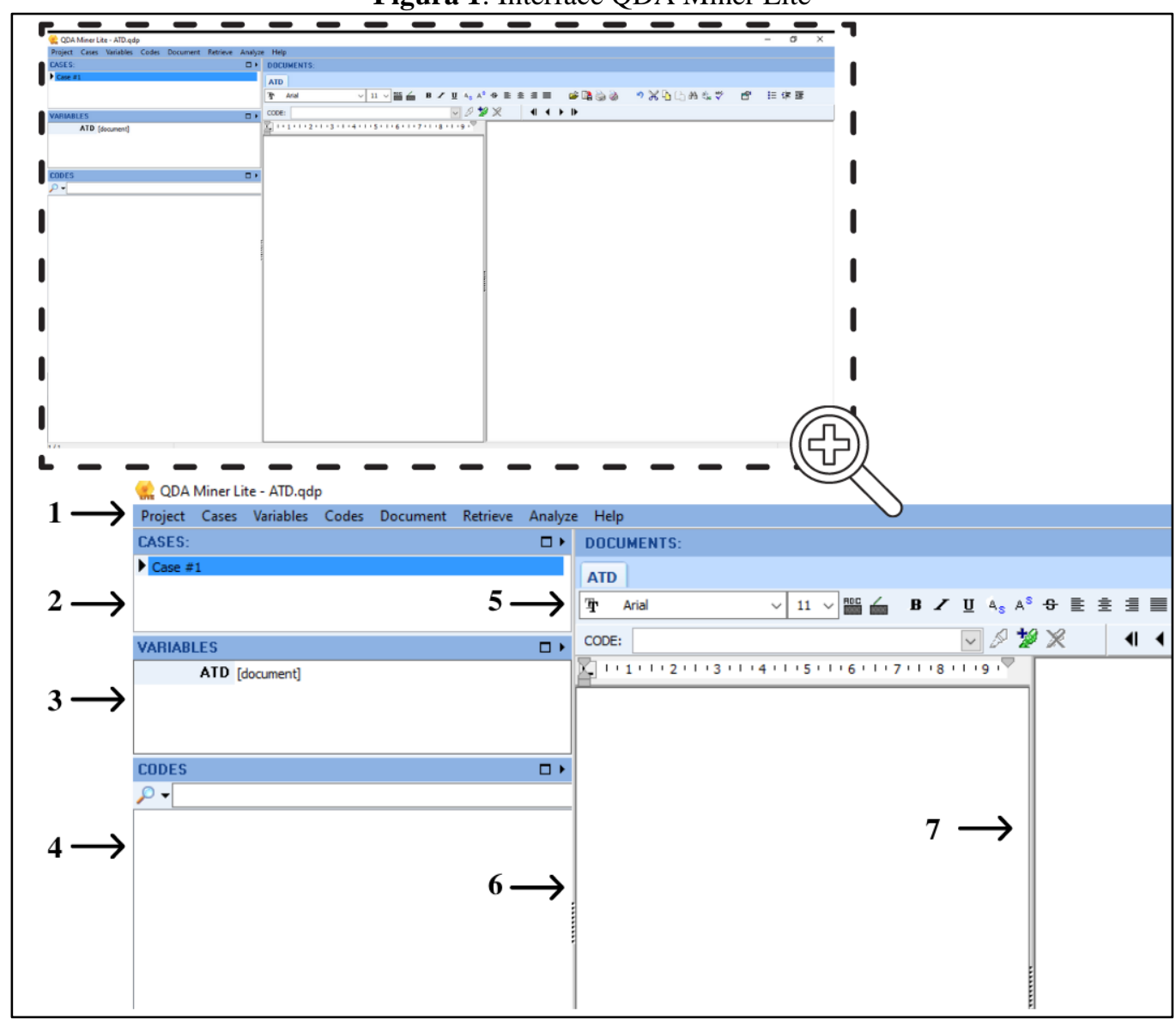

Fonte: QDA Miner Lite (2020)

O programa possui uma interface intuitiva, facilitando o seu manuseio. Cada campo do software auxilia o pesquisador a organizar seu trabalho, contribuindo para a análise dos materiais. Apresenta-se da seguinte forma:

1- Na barra de ferramentas, encontram-se as seguintes abas: Project, onde são salvas as alterações realizadas, abertos projetos já existentes e exportados arquivos para dentro do programa; a aba Cases é utilizada de acordo com a necessidade do pesquisador analisar um ou mais documentos, podendo editar vários casos dentro de um mesmo projeto; Variables indica o tipo de arquivo e demais ferramentas não disponíveis na versão gratuita; já na aba Codes são adicionadas as categorias e respectivas subcategorias, atribuindo cores diferentes para cada código elencado; em Document a principal função utilizada é o destaque do texto de acordo com a opção do pesquisador, como por exemplo, destacando as cores de cada categoria e subcategoria; na aba Retrieve o pesquisador pode buscar por palavras-chave no material bem como visualizar todas as frases codificadas, com a opção de exportar em planilhas e documentos de texto; por fim, em Analize é possível extrair a frequência de cada categoria e quantidade de palavras categorizadas, também com a possibilidade de baixar em formato de imagem. 
2- Listagem de casos do projeto e qual caso está selecionado para análise.

3- Espaço onde aparecem as variáveis, caso as haja.

4- Lista das categorias e subcategorias.

5- Barra de ferramentas de edição de texto.

6- Espaço onde aparecerá o corpus em análise.

7- Indica as codificações realizadas ao longo do texto.

Esses recursos disponíveis no software auxiliam o pesquisador na organização das etapas da Análise Textual Discursiva, oportunizando a exploração aprofundada do corpus da investigação. Para melhor ilustrar, apresenta-se o trabalho realizado em duas dissertações de mestrado (DOMICIANO, 2019; GERALDO, 2020), realizadas no âmbito do Grupo de Estudos e Pesquisa em Alfabetização Científica e Tecnológica (GEPACTUFPR), que utilizaram o QDA Miner Lite no processo de análise à luz dos referenciais da ATD.

\section{Unitarização}

Seguindo a primeira etapa da Análise Textual Discursiva, a unitarização, (MORAES; GALIAZZI, 2006), Geraldo (2020) agrupou todo o corpus que compôs sua investigação em um único projeto no QDA Miner Lite. Cada técnica de constituição de dados (entrevistas, análise de documentos e observação) se tornou um caso específico, dando a flexibilidade necessária para a visualização total do material constituído sem ocultar a sua origem.

Figura 2: Organização de projetos e casos de análise de Geraldo (2020)

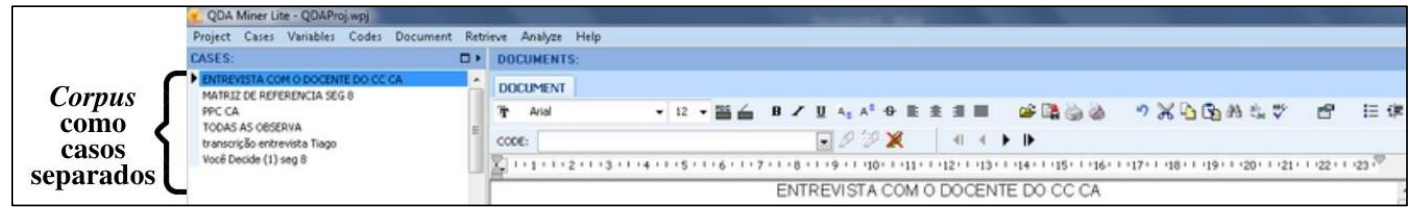

Fonte: QDA Miner Lite (2020)

Já na pesquisa de Domiciano (2019), devido ao grande volume de dados constituídos para o corpus, foi necessária a organização de quatro projetos com seus respectivos casos. Nesta situação, cada técnica de constituição de dados foi materializada em um projeto e as suas variações se tornaram os casos. Como exemplo, a observação participante realizada em duas turmas de um curso de graduação, ao longo de 18 aulas, 
de forma que para cada turma foi estruturado um projeto, e cada aula assistida nas respectivas turmas se tornou um caso, conforme ilustrado na Figura 3.

Figura 3: Organização de projetos e casos de análise de Domiciano (2019)

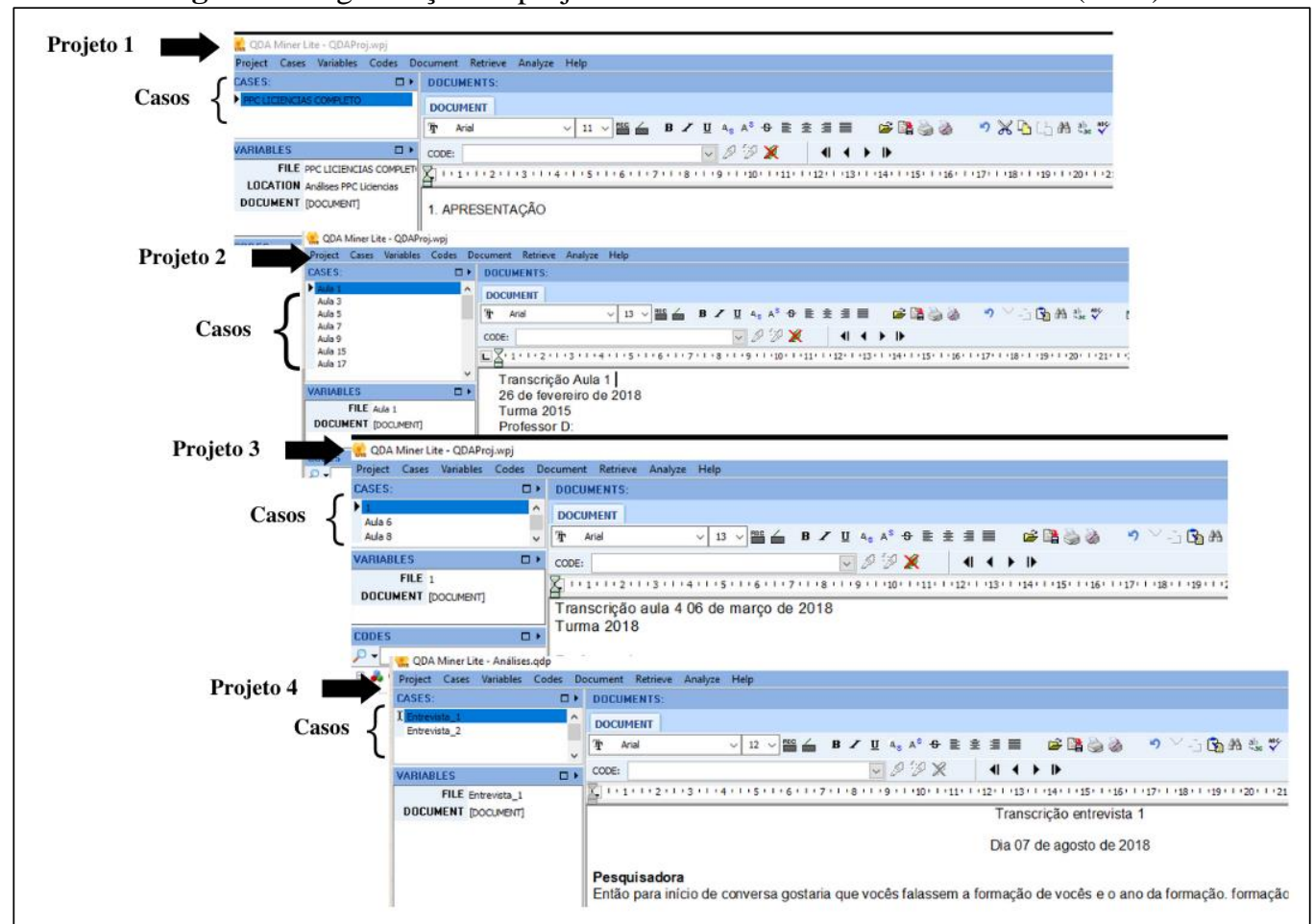

Fonte: QDA Miner Lite (2020)

Com todo o corpus organizado, o material foi trabalhado. Foi realizada a leitura, a releitura e a separação das frases, parágrafos ou palavras confluentes entre si conforme as categorias estabelecidas a priori, resultantes das pesquisas bibliográficas empreendidas por Domiciano (2019) e Geraldo (2020), dando início a fase de codificação das unidades de sentido. A Figura 4 ilustra o processo. 
Figura 4: Processo de Unitarização e codificação no QDA Miner Lite

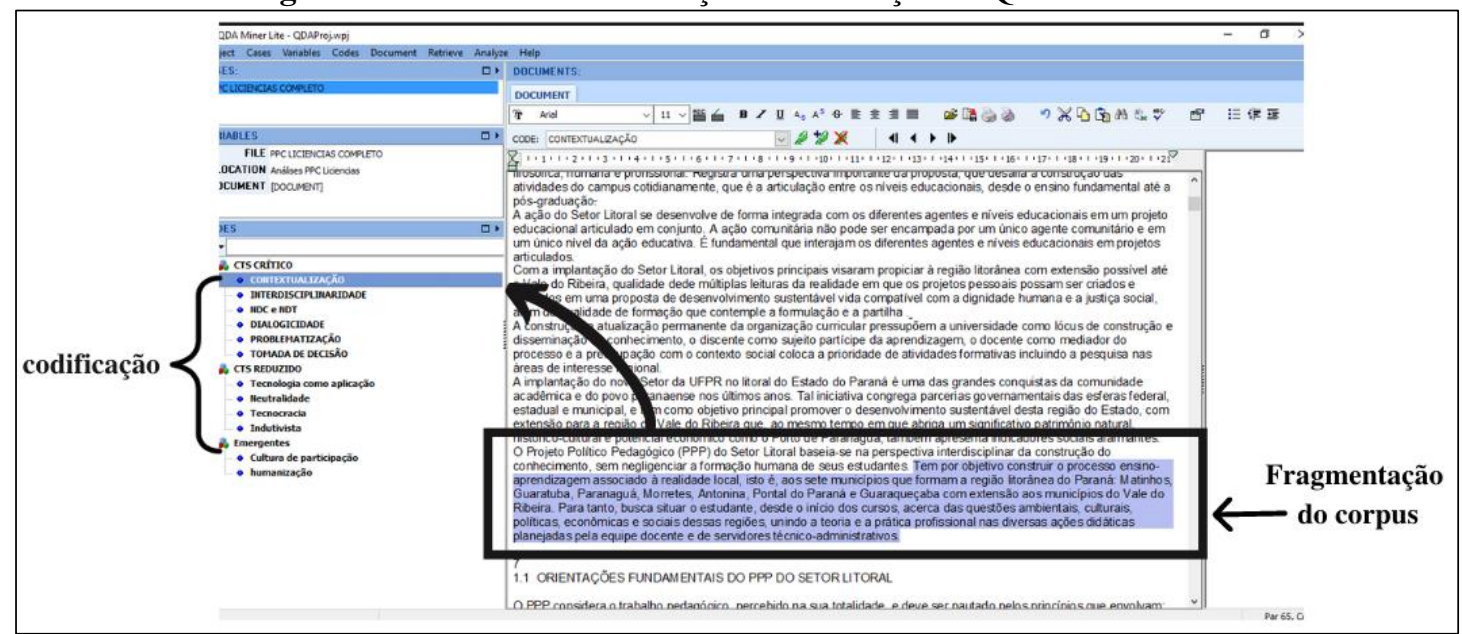

Fonte: QDA Miner Lite (2020)

A orientação por categoria e subcategorias a priori não impediu a identificação de unidades de sentido emergentes e suas respectivas codificações, anunciando assim, outros movimentos importantes de reflexão, indo ao encontro dos prícipios da ATD colocados por Moraes e Galiazzi (2006). Dessa forma, o processo de codificação se deu mais intensamente na identificação de unidades de sentido emergentes, ou seja, aquelas diferentes das categorias a priori. O processo de reescrita das unidades de sentido se deu por meio do destaque em negrito das palavras, frases ou parágrafos, sendo a parte destacada em negrito considerada a unidade de sentido que seria utilizada no processo de categorização.

\section{Categorização}

A categorização ocorreu por meio da organização das codificações realizadas, a priori e emergentes. Como já explicado anteriormente, o processo de identificação de unidade de sentido das categorias a priori decorreu de forma mais objetiva, pois Domiciano (2019) e Geraldo (2020) já haviam realizado pesquisas extensas e também estavam familiarizadas com a teoria empregada em suas dissertações. Contudo para diminuir o risco da interpretação inadequada, as categorizações foram realizadas respeitando o proposto na ATD, sobre a necessidade do afastamento do trabalho e posterior retomada, para que possíveis "vícios" de leitura e compreensão possam ser combatidos (MORAES; GALIAZZI, 2006). A Figura 6 apresenta a categorização realizada por Domiciano (2019). 
Figura 5: Categorização de Domiciano (2019)

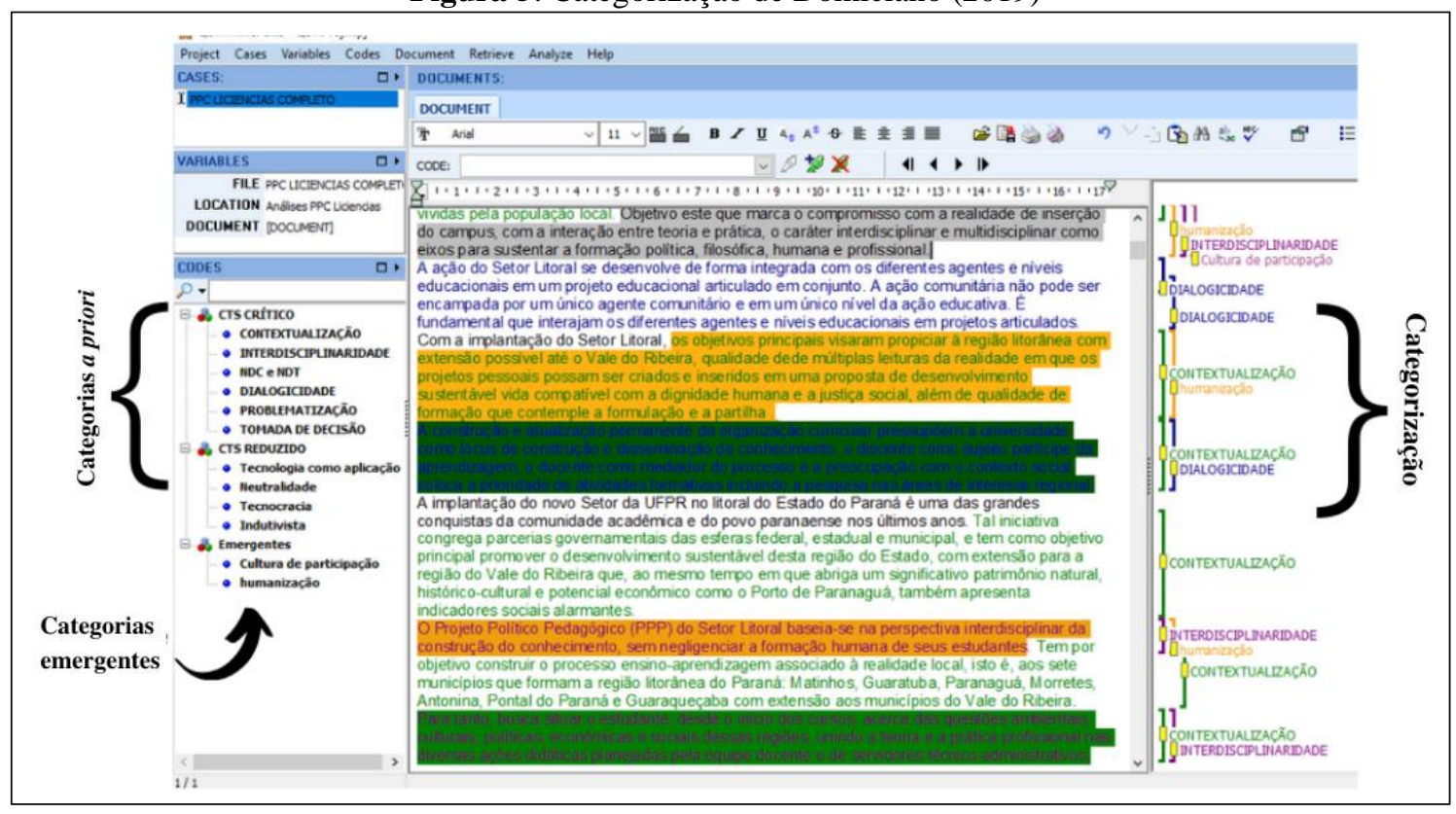

Fonte: QDA Miner Lite (2020)

Dentre as ferramentas disponíveis no software QDA Miner Lite se encontra a função de atribuir a cada categoria e subcategoria diferentes cores, destacando ao longo do texto cada unidade selecionada. Esse processo auxilia o pesquisador a ir visualizando as categorias sendo construídas e identificando trechos do corpus que ainda não foram categorizados, diminuindo consideravelmente a possibilidade de perda de elementos importantes. Esta função da ferramenta também contribui para leituras e releituras mais atentas, favorevendo categorizações mais fidedignas com as unidades de sentido.

Mais adiante, para a visualização de todas as categorias e subcategorias, o software QDA Miner Lite possui a função Retrieve Segments que pode gerar de forma separada cada categoria/subcategoria ou então uma visualização geral da análise, com todas as categorias/subcategorias e seus respectivos materiais empíricos e unidades de sentido, conforme é exposto na Figura 6. 
Figura 6: Categorização e visualização das unidades de sentido de Geraldo (2020)

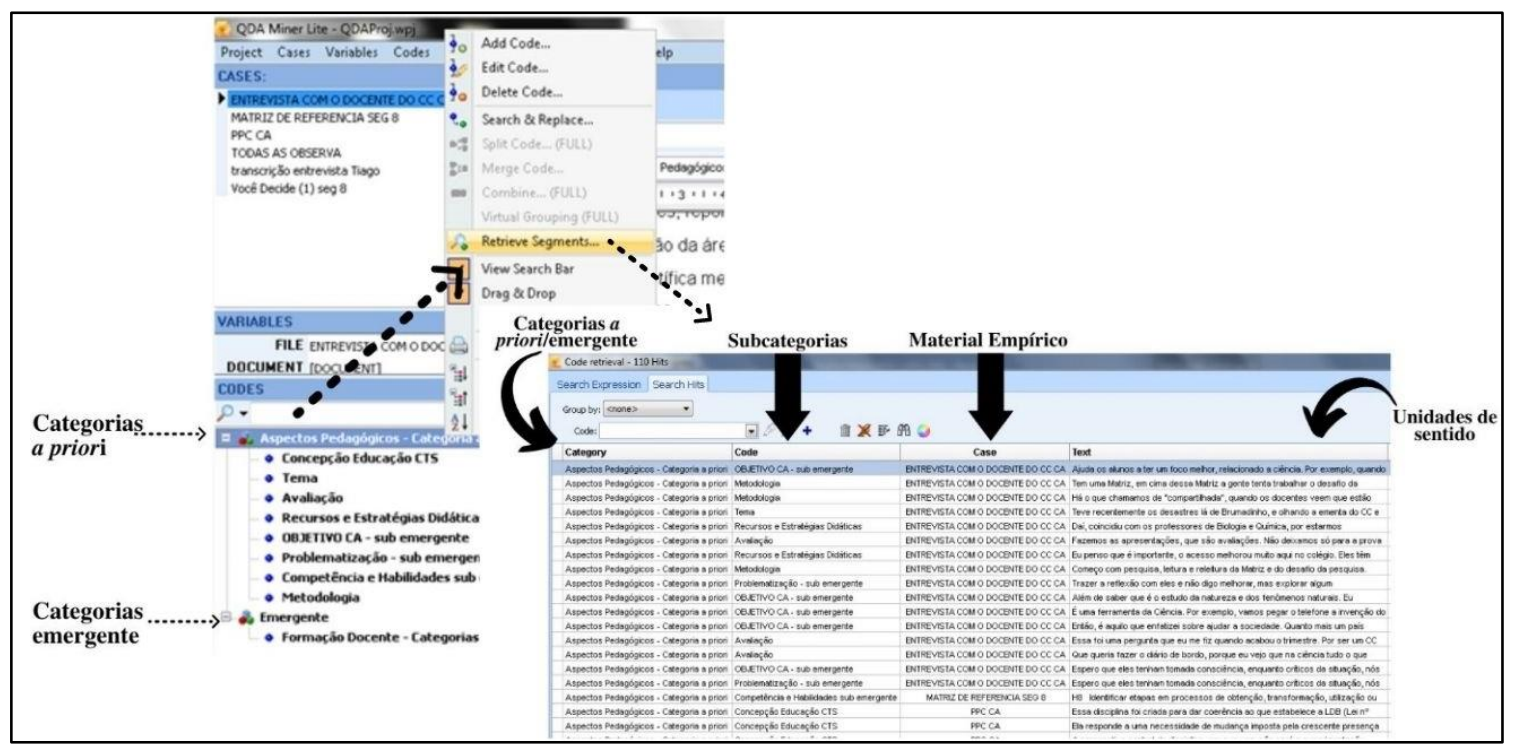

Fonte: QDA Miner Lite (2020)

Fica evidente o modo como o software QDA Miner Lite contribui com o processo da Análise Textual Discursiva até a presente etapa. O programa auxilia na organização da área de trabalho, favorecendo a visualização da formação das unidades de sentido e categorias. A ferramenta não torna o processo automático, mas, pelo contrário, ela permite a leitura completa do corpus a ser analisado, de forma fluída e contínua, diminuindo consideravelmente o risco de elementos essenciais passarem desaperbidos.

\section{Metatextos}

$\mathrm{Na}$ fase final da ATD, a construção de metatextos, nas pesquisas de Domiciano (2019) e Geraldo (2020), se deu inicialmente por meio da descrição das categorias/subcategorias a priori e/ou emergentes, ou seja, o que siginficam essas categorias conforme a concepção do pesquisador. Em seguida, as autoras deram inicio às discussões das unidades de sentido, aliando as interpretações com os fundamentos teóricos, em um movimento de busca por teorizações para explicar o fenômeno estudado.

É importante ressaltar o caráter flexível e fluido que a ATD e a organização do QDA Miner Lite possibilitou na construção de análise, pois foi durante a construção dos metatextos também, que Geraldo (2020) sentiu a necessidade de retomar a análise no software QDA Miner Lite para rever suas codificações e (re) categorizar, criando, assim, uma nova categoria e novas subcategorias.

A escrita do metatexto é o momento da ATD em que o autor expressa as interpretações realizadas ao longo de toda a análise, tomando formas distintas de acordo 
com como o pesquisador vai percorrendo por este caminho. O software, neste momento, auxilia apenas na importação das unidades de sentido de forma organizada, conforme a Figura 7, ficando sob incumbência do autor a produção textual.

Figura 7: Categoria salvas em Doc. e Xls. para a construção dos metatextos

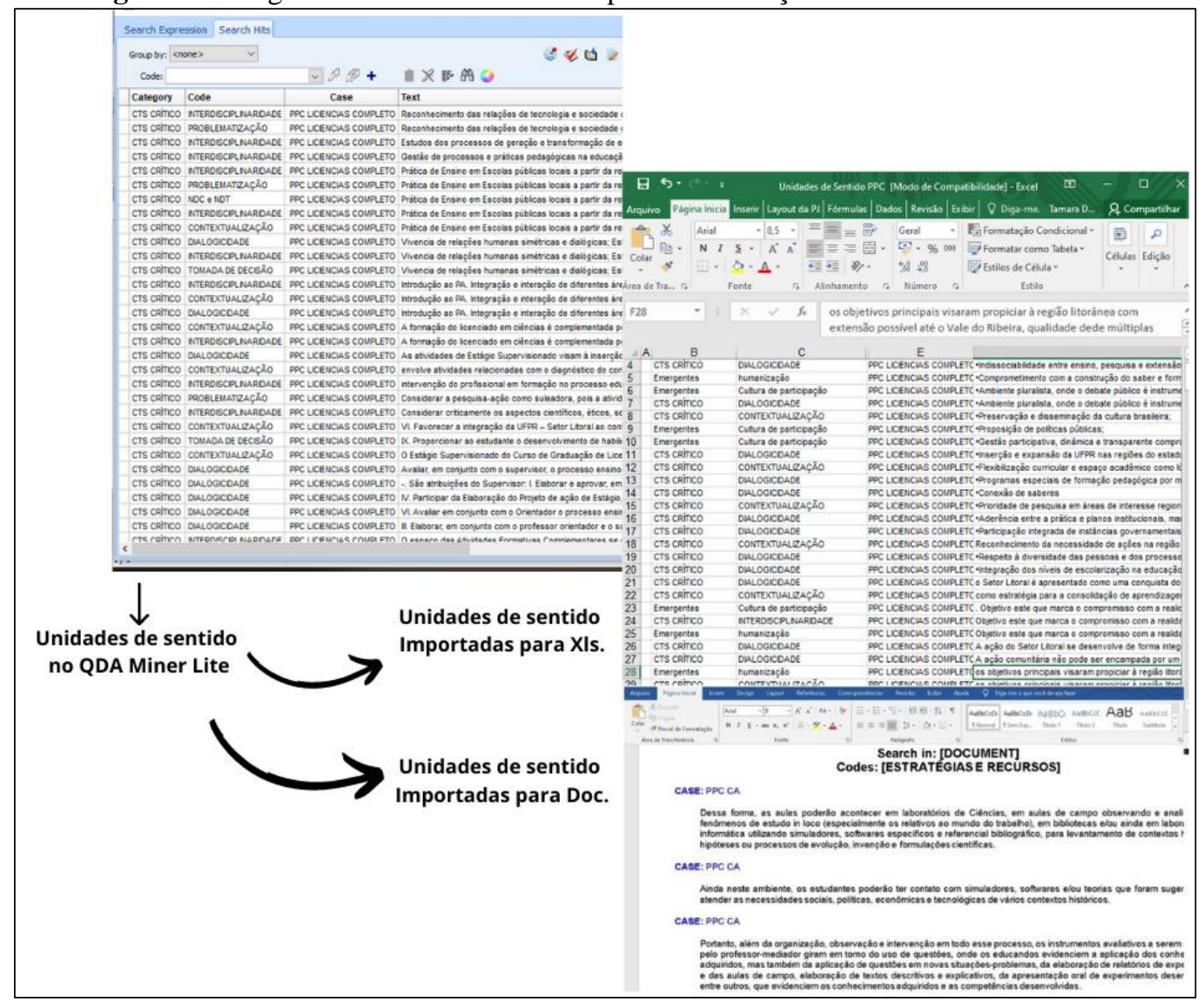

Fonte: QDA Miner Lite (2020)

As unidades de sentido podem ser extraídas em formato Doc. ou Xls., possibilitando a visualização desta nova organização do material. Geraldo (2020) optou pelo formato em Doc. por ter se adaptado melhor à visualização das unidades de sentido, que acontece no tempo real da escrita dos seus metatextos. Já Domiciano (2019) exportou o material no formato Xls. por ter maior familiaridade com o programa. Isso demonstra que o QDA Miner Lite é adaptável à necessidade de cada pesquisador.

O software também possibilita ao pesquisador realizar a análise quantitava do que foi codificado, apresentando os valores por categoria e subcategoria, demonstrando-os em forma de quantidade numérica, porcentagem em relação ao total e qual porcentagem dos casos representa. Na Figura 8, é demonstrada a análise quantitativa realizada por Domiciano (2019). 
Figura 8: Categorização e Unidades de Significado de Domiciano (2019)

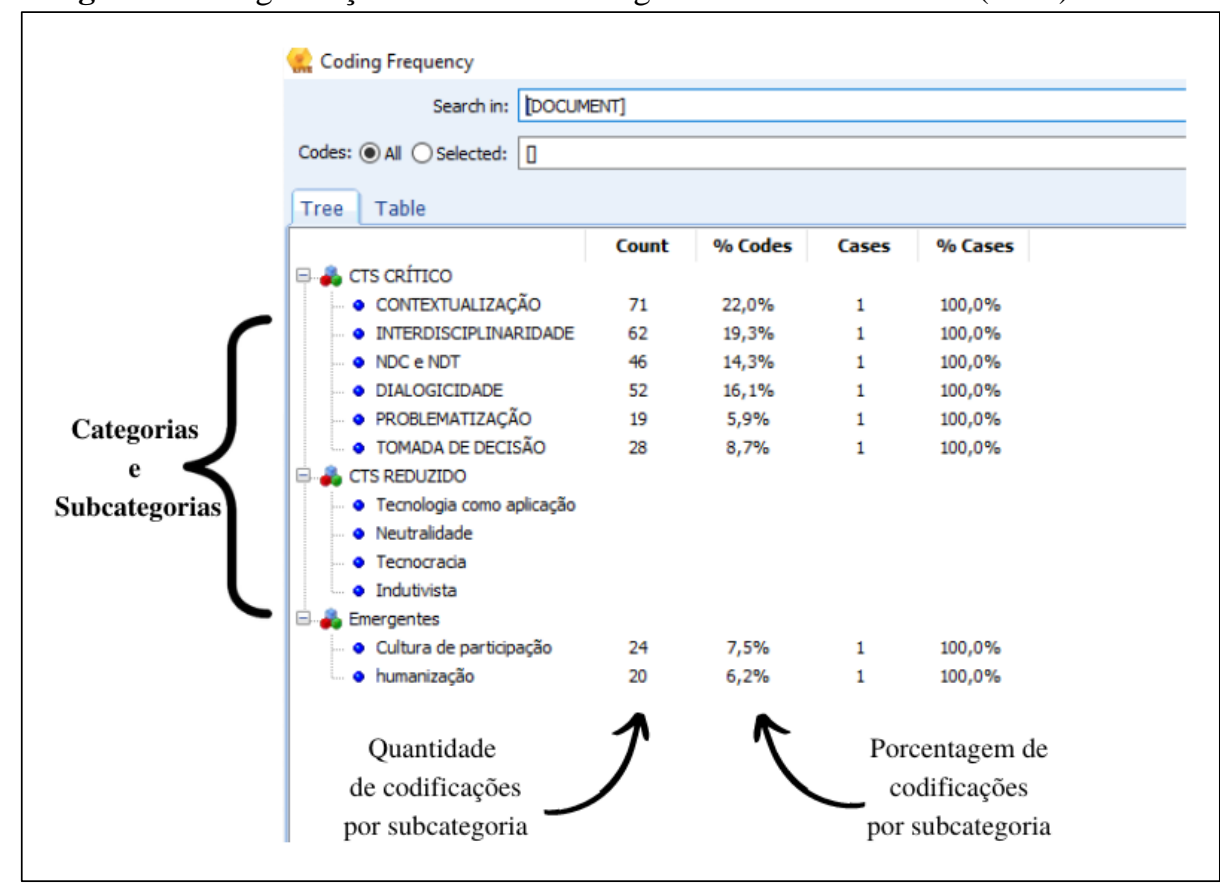

Fonte: QDA Miner Lite (2020)

Essas informações quantitativas foram discutidas ao longo do metatexto produzido por Domiciano (2019), entendendo que o demonstrativo numérico de frequência das unidadades de sentido auxiliariam na compreensão do fenômeno estudado. Esta discussão também contribuiu para indicar a maior presença de uma determinada abordagem educacional em detrimento de outra, contribuindo para o objetivo da pesquisa desenvolvida.

Diante do exposto, é notória a contribuição do software quando aliada à ATD. Todavia, não no sentido de simplificar as etapas, mas sim de aprimorar o processo diminuindo as possibilidades de falhas e lacunas, enriquecendo a investigação e atribuindo maior fidedignidade às análises dos dados constituídos ao longo das investigações, para que a última etapa da ATD, a construção dos metatextos, possa ser empreendida de forma mais significativa e autêntica.

\section{Considerações}

O objetivo deste trabalho foi analisar o uso do QDA Miner Lite no processo de desconstrução, unitarização e categorização do corpus, etapas da metodologia de Análise Textual Discursiva. Para tanto, foram explorados os percursos realizados por duas investigações desenvolvidas no Grupo de Estudos e Pesquisas em Alfabetização Científica e Tecnológica (GEPACT) da Universidade Federal do Paraná. 
Por meio do exposto ao longo deste trabalho, ficam evidente as contribuições do uso do software para o desenvolvimento da Análise Textual Discursiva. Os recursos disponíveis ao pesquisador, mesmo na versão gratuita, que é reduzida, propiciam a organização de todo o corpus, favorecendo a leitura e a interpretação do material para o primeiro momento da ATD.

Para mais, realizada a unitarização, o QDA Miner Lite favorece a sistematização das categorias a priori, bem como a visualização das categorias emergentes, e do destaque do texto, que se realiza ao mesmo tempo da codificação. Já em relação à última fase da Análise Textual Discursiva, a construção dos metatextos, o software auxilia na geração automática de planilhas e/ou documentos de texto, com as unidades de sentido categorizadas, bem como também possibilita a importação de dados numéricos em relação à codificação.

Ressalta-se que a prática de utilizar o programa QDA Miner Lite no âmbito do GEPACT iniciou com as duas pesquisas citadas e, posteriormente, foi realizado um encontro de formação com os demais integrantes da equipe para o uso do software, aliado a metodologia da Análise Textual Discursiva. Destaca-se também que há pesquisas em andamento que adotarão o uso do programa, tendo em vista o aprimoramento dos trabalhos desenvolvidos.

Em suma, em todo o percurso das duas pesquisas discutidas neste trabalho, percebe-se que a análise não foi realizada de forma automatizada, com o programa realizando o trabalho sozinho e gerando um resultado no final. Assim, não se trata de eximir o papel do pesquisador na interpretação dos resultados, e sim de fornecer a ele uma ferramenta para amparar o seu trabalho, descomplicando um dos momentos mais complexos das investigações acadêmicas, que é a análise.

\section{Referências}

BARDIN, L. Análise de conteúdo. 70. ed. Lisboa: Edições 70, 1979.

CHARMAZ, K. A construção da Teoria Fundamentada: guia prático para a análise qualitativa. Trad. Joice Elias Costa. Porto Alegre: Artmed, 2009.

CHARMAZ, K. The power and potential of Grounded Theory. Medical Sociology online, [S.I.], v. 6, n. 3, p. 1-14, out. 2012.

DOMICIANO, T. D. Enfoque CTS no curso de Licenciatura em Ciências. 2019. Dissertação (Mestrado em Educação em Ciências e em Matemática) - Universidade Federal do Paraná, Curitiba, 2019. 
FLICK, U. Métodos qualitativos na investigação científica. 11. ed. Lisboa: Monitor, 2005.

GARCIA, F. M; ESTÊVÃO, C. Uma experiência de análise de conteúdo com uso de QDA's. In: CONGRESSO IBERO-AMERICANO EM INVESTIGAÇÃO QUALITATIVA. 5., 2016, Porto. Atas... Porto: Ludomedia, v. 4, 2016. p. 45-2,

GERALDO, A. P. Aspectos didáticos e pedagógicos da Educação CTS no Ensino Médio: uma análise do componente curricular ciências aplicadas da rede SESI-PR. 2020. Dissertação (Mestrado em Educação em Ciências e em Matemática) - Universidade Federal do Paraná, Curitiba, 2020.

GIL, A. C. Métodos e técnicas de pesquisa social. 5.ed. São Paulo: Atlas, 1999.

GRONDIN, J. Hermeneutica. Editora: Parábola, 2012.

MINAYO, M. C. de S. et al. Pesquisa social: teoria, método e criatividade. 21. ed. Petrópolis: Vozes, 1994

MORAES, R. Uma tempestade de luz: a compreensão possibilitada pela análise textual discursiva. Ciência \& Educação, Bauru, v. 9, n. 2, p. 191-211, outubro. 2003.

MORAES, Roque; GALIAZZI, Maria do Carmo. Análise Textual Discursiva: processo reconstrutivo de múltiplas faces. Ciência \& Educação, Bauru, v. 12, n. 1, p. 117-128, 2006.

MORAES, R.; GALIAZZI, M. do C. Análise textual discursiva. 2. ed. Ijuí: Editora Unijuí, 2011.

NERI DE SOUZA, D.; NERI DE SOUZA, F.; COSTA, A. P. Percepção dos utilizadores sobre o software de análise qualitativa webQDA. Comununicação e Informação, Goiânia, v. 17, n. 2, p. 104-118, jul./dez. 2014.

ORLANDI, E. P. Análise de Discurso - Princípios e Procedimentos. 5. ed. Campinas: Pontes, 2003.

SALVADOR, P. T. C. de O. et al. Software de análise de dodos qualitativos utilizados nas pesquisas da Enfermagem. Texto \& Contexto Enfermagem, Florianópolis, v. 28, p. 1-14, nov. 2019.

TEIXEIRA, E. B. A Análise de Dados na Pesquisa Científica importância e desafios em estudos organizacionais. Desenvolvimento em Questão, Unijuí, v. 1, n. 2, p. 177-201, jul./dez. 2003.

Recebido em: 30 de outubro de 2020 .

Aceito em: 12 de novembro de 2020. 